\title{
Políticas curriculares: a luta pela significação no campo da disciplina História
}

\author{
Ana de Oliveira \\ Universidade do Estado do Rio de Janeiro, Brasil
}

\section{Resumo}

Este artigo tem como foco a atuação da comunidade disciplinar de História, na interface que essa comunidade estabelece com o ensino da disciplina e com as políticas curriculares no Brasil, nos anos de 1980. Tendo como matriz a concepção de currículo que confere centralidade aos conceitos de poder e cultura, articulo os aportes teórico-metodológicos da História das Disciplinas Escolares a outras noções, conceitos e categorias tomadas da Teoria do Discurso. Apresento como, no caso brasileiro, um número significativo de atores sociais esteve envolvido em múltiplos processos de articulação e expressou, em textos e discursos, diferentes tendências em relação ao ensino da disciplina. Concluo indicando possíveis questões suscitadas pela análise do Decreto-lei $n^{\circ} 43 / 2007$, que em Portugal regula o Mestrado em Ensino de História e Ensino de Geografia, destacando a tensão entre as disciplinas História e Estudos Sociais.

Palavras-chave

Estudos Sociais; Políticas curriculares; Teoria do Discurso

A temática deste artigo situa-se no âmbito das políticas curriculares, no Brasil, dos anos de 1980, e sua abordagem é orientada por uma concepção de currículo em que as noções de cultura e poder adquirem centralidade. Penso o currículo como arena de lutas na qual diferentes demandas, defendidas por múltiplos sujeitos, são postas em disputa em busca da hegemonia de um projeto curricular, portanto, como política cultural. Como tal, 
é "uma luta discursiva pela constituição de representações que envolve negociação, isto é, articulação discursiva na qual alguns grupos particulares buscam defender determinadas demandas curriculares e para tal constituem representações" (Lopes, 2010). É nesse sentido que, a partir da análise de textos e discursos produzidos pelo grupo disciplinar de História, ou, como em Goodson (1997), pela comunidade disciplinar, busco compreender as estratégias políticas empreendidas por esses sujeitos frente à hegemonização da disciplina Estudos Sociais e do projeto curricular que, nos anos de 1980, questionou a prioridade até então assumida pela disciplina História nos currículos das escolas de Educação Básica e das universidades.

Na perspectiva dessa concepção curricular, busco nos aportes teóricos do Ciclo Contínuo de Políticas (Ball, 1989; Ball \& Bowe, 1998) argumentos para defender uma micropolítica no estabelecimento das políticas curriculares, superando a concepção de políticas em uma perspectiva de centralidade do Estado e da dicotomia proposta/implementação presente em muitos estudos do campo curricular. A micropolítica, como sistema e prática, é capaz de definir estratégias que recontextualizam as finalidades do processo de escolarização representadas em diferentes propostas curriculares. Essas finalidades são definidas por intermédio de processos articulatórios que implicam conflitos gerados em função de valores e interesses defendidos por grupos sociais diversos.

Recorro, também, ao modelo analítico da 'História das Disciplinas Escolares' (Goodson, 1997, 2007), tendendo a aceitar a concepção de que a disciplina escolar é parte de uma estrutura mais ampla que incorpora e define os objetivos e possibilidades sociais do ensino e que desempenha papel importante na fixação de parâmetros do que deve ou não ser ensinado. Nos campos discursivos que as políticas atravessam, quando se consideram as instituições de ensino e as diferentes disciplinas, processos articulatórios fazem imbricar não só finalidades educacionais e institucionais, mas, sobretudo, finalidades disciplinares.

No sentido de reconfigurar esses modelos analíticos, reúno argumentos para defender que a Teoria do Discurso pode favorecer a interpretação do Ciclo de Políticas sem dicotomizar proposta e implementação, bem como aprofundar a interpretação da microestrutura disciplinar para além da ideia de conhecimento disciplinar como totalidade 
definida por parâmetros estritamente epistemológicos. Apresento, em subitens, na primeira parte desse artigo, a postura epistêmica que me possibilitou a análise das políticas curriculares que, no Brasil, nos anos de 1980, hegemonizaram a disciplina Estudos Sociais, buscando articular os aportes teórico-metodológicos da História das Disciplinas Escolares (HDE) de Ivor Goodson e do Ciclo de Políticas de Stephen Ball a outras noções, conceitos e categorias tomadas da Teoria do Discurso.

$\mathrm{Na}$ segunda seção, apresento como, no caso brasileiro, um número significativo de atores sociais reunidos em torno da comunidade disciplinar de História, identificada na Associação Nacional de História (ANPUH), esteve envolvido, nos anos de 1980, em múltiplos processos de articulação e expressou, em textos e discursos, diferentes tendências em relação ao ensino da disciplina, indicando como os processos articulatórios culminaram na extinção da disciplina Estudos Sociais, hegemonizada nos textos curriculares brasileiros do período em questão ${ }^{1}$.

Por fim, indico, na última seção, questões suscitadas pela análise do Decreto-Lei $n^{\circ} 43 / 2007$, que em Portugal regula o Mestrado em Ensino de História e Ensino de Geografia, indicador da concretização de uma concepção inaugurada no período pós-1974 e reafirmada pelo Processo de Bolonha. Em Portugal, diferentemente do Brasil, a perda da autonomia da disciplina História em favor da sua junção à disciplina Geografia, se deu em um contexto de democratização política e teve como motivação, dentre outras, o cumprimento de uma agenda política que visava a aumentar a obrigatoriedade dos anos de escolaridade, e adequar a formação docente à necessidade de corrigir os déficits que a educação portuguesa apresentava ${ }^{2}$. Nesse momento, assumo os limites impostos pela impossibilidade de partir da análise de uma tradição que poderia ser denominada portuguesa. Como discute Mouffe (1996), a tradição permite compreender o "fato de sermos criados como sujeitos através de uma série de discursos existentes, e que é através desta tradição que nos forma que o mundo nos é dado e toda a ação política [encarada como intimação] é tornada possível" (idem, p. 30). Ainda assim, defendo a pertinência da análise em nome de uma leitura através de outras tradições, as quais podemos denominar brasileiras. É assumindo o lugar do Outro, de uma leitura estrangeira e, portanto, negociando com outras tradições, que a produção deste texto se faz. 
Acredito que este trabalho possa contribuir para a ampliação das pesquisas que têm como temática as políticas curriculares, justamente por disponibilizar essa leitura de outro lugar e de outra tradição que estenda as parcerias que, em inúmeras publicações, em regime de co-produção, vêm aproximando investigadores portugueses e brasileiros do campo do currículo.

\section{Reconfigurando a postura epistêmica de análise}

A construção de um modelo analítico para a compreensão de um objeto de pesquisa implica um movimento de articulação como postura epistêmica (De Alba, 2007, p. 39). Essa postura requer a apresentação das noções, dos conceitos e das categorias fundamentais que precisam ser defendidas como sendo as melhores para a investigação, e as escolhas, tomadas como sendo as mais adequadas, imbricam-se a outras, também possíveis, que redesenham, por sucessivas ressignificações, a configuração teórica que se adota na investigação. Neste trabalho, o movimento de articulação busca conectar os aportes teórico-metodológicos da História das Disciplinas Escolares de Ivor Goodson (HDE) e noções, conceitos e categorias tomadas da Teoria do Discurso de Ernesto Laclau, visando a superar as lacunas que os primeiros apresentam, se considerada, na análise, a concepção de currículo que adoto.

\subsection{A História das Disciplinas Escolares: aproximações e afastamentos}

Nesse movimento de reconfiguração teórica, a HDE contribui com algumas concepções que considero potentes para a compreensão das políticas curriculares. Destaco, dentre elas, o entendimento das disciplinas como "construídas social e politicamente através de processos onde os atores envolvidos [nesta construção] empregam uma gama de recursos ideológicos (sentido simbólico) e materiais (sentido prático) para levarem a cabo as suas missões individuais e coletivas" (Goodson, 1997, p. 27), retirando de foco, nessa perspectiva, as bases epistemológicas da constituição dessas disciplinas.

Considero potente na HDE a categorização que diferencia as disciplinas - escolar, acadêmica, científica -, entendendo, com Goodson 
(1997), que a diferenciação que se possa estabelecer entre essas modalidades precisa considerar as finalidades específicas a que cada uma delas atende, abandonando qualquer forma de hierarquização entre essas modalidades (Oliveira, 2006, 2011a, 2011b). Ainda na perspectiva da HDE, tendo a aceitar a atuação de uma rede de profissionais de um campo científico específico - a comunidade disciplinar -, constituída por pesquisadores no ensino das disciplinas e no campo do conhecimento de referência e por professores nas escolas e universidades, na definição das políticas curriculares através da multiplicidade de representações que essa rede organiza. Nesse sentido, defendo, com Goodson, uma micropolítica disciplinar na compreensão das políticas curriculares.

Entretanto, outras concepções desse modelo analítico, na orientação curricular enunciada para este trabalho, apresentam lacunas que carecem de ajustes teóricos. A primeira delas refere-se à concepção historiográfica na qual Ivor Goodson (1997) ancora seu modelo analítico: a História das Mentalidades. A escolha dessa concepção acaba por fazer prevalecer as determinações do macro-contexto na constituição das disciplinas e de leis históricas no entendimento da constituição das comunidades disciplinares. Tendo a aceitar a ideia de que essa opção, em Goodson, atende à sua perspectiva de compreender as disciplinas escolares a partir de uma estrutura contextual macro que se apresenta como limitadora das ações de sujeitos na constituição de cada uma das disciplinas que compõem o currículo.

Relacionada ao movimento da Escola dos Annales que, na França, desde o final da década de 1920, passou a questionar as marcas positivistas que a História apresentava - forte preocupação com os acontecimentos políticos, a apologia de príncipes ou generais em feitos singulares, dentre outras características -, a História das Mentalidades visa à reconstrução de fatos em série, que permite a compreensão totalizante da sociedade, apresentando-se como a teoria capaz de levar a efeito as pesquisas históricas no sentido de ressaltar "a 'mentalidade' de uma pessoa ou sociedade ou ainda uma cultura e analisar as linhas de força, poder e conexão interativamente estabelecidas nas tensões indivíduo-coletividade" (Provetti, 2009). Esses pressupostos possibilitam a Goodson a defesa do que denomina 'teoria do contexto', orientando suas pesquisas no sentido de não flexibilizar os moldes 
rígidos e determinantes da estrutura e a não considerar as ações de sujeitos como diferenças que se articulam em um campo de negociações ou, em outros termos, como ações contingentes em um espaço de conflito no sentido da hegemonização de determinado projeto político.

Com relação ao eixo curricular, outra base que sustenta a HDE, Goodson, ultrapassando os limites das concepções instrumentais de currículo que apresentam os saberes disciplinares como repertórios estáveis legitimados por critérios epistemológicos, apresenta a organização curricular disciplinar como estratégia de manutenção das desigualdades sociais, seguindo a trilha conceitual das teorias críticas. Alinhando-se a essas teorias, tende a compreender a constituição das diferentes disciplinas a partir de determinismos econômicos e de classes (Soares, 2009). Estudos recentes apontam que a tendência de substituição dos currículos disciplinares por currículos integrados por áreas ou por competências (Lopes, 2008), além de manter a lógica disciplinar, não representa o fim das desigualdades sociais, projeto que permanece caro aos sujeitos da educação.

Mesmo considerando que, na constituição curricular, uma variedade de sujeitos no âmbito do Estado, no âmbito de cada uma das instituições escolares e acadêmicas e no âmbito disciplinar interfere no delineamento do currículo, Goodson considera, em seus estudos, os documentos curriculares escritos como "racionalidades escolhidas e como a retórica legitimadora das práticas pedagógicas" (Goodson, 1997, p. 20), reforçando a dicotomia entre currículo ativo e currículo pré-ativo, este último entendido como responsável pela manutenção das desigualdades sociais. Lopes \& Macedo (2011a), a partir da análise de teses e dissertações sobre o campo do currículo no Brasil, problematizam essa distinção, concluindo que os estudos do campo curricular, ao trazerem para análise as experiências de sala de aula, não alteraram a lógica do currículo como prescrição, mantendo "uma concepção hierarquizada de poder - seja de cima-para-baixo seja de baixo-para-cima que dificulta a possibilidade de pensar o currículo para além da prescrição" (idem, p. 99).

Temos avançado, no Grupo de Pesquisa 'Políticas de currículo e

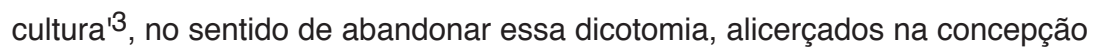
do Ciclo Contínuo de Políticas de Stephen Ball (1989, 1998). Para esse autor, os textos curriculares incorporam sentidos que circulam em campos 
discursivos diversos, incluindo neles o que denomina de contexto da prática. Suas pesquisas apontam que os textos das políticas são recontextualizados por hibridismo (Ball, 1989; Ball \& Bowe, 1998; Lopes, 2005), e os sentidos que se pretendem hegemônicos são ressignificados por uma multiplicidade de sujeitos em meio a processos articulatórios. Na perspectiva desse autor, a dicotomia - embora muitas vezes enunciada - tende a dissolver a separação entre proposta e implementação, caminhando para uma concepção em que ambos são considerados como integrantes do que denominam currículo.

Goodson reconhece e inclui nos processos de definição do currículo a atuação de uma multiplicidade de sujeitos, reunidos na categoria que denomina 'comunidade disciplinar'. Para o autor, a comunidade disciplinar tem ação decisiva na produção das políticas curriculares, mas na perspectiva da HDE essa concepção acaba por deslizar no sentido de manter a dicotomia entre as duas categorias conceituais de currículo escrito e currículo em ação.

Considero importante ainda indicar a forma como na HDE se concebe as categorias sujeito e conhecimento, apresentando as lacunas que essa concepção apresenta e a forma como busco superá-la. Goodson, em diálogo com Giddens (apud Goodson, 1997), entende que a ação de sujeitos na constituição das disciplinas reproduz as propriedades estruturais do contexto mais amplo e é delimitada por regras específicas definidas e determinadas pela macro-estrutura. Entende, também, que as mudanças nessa macroestrutura, afastada cada vez mais da consecução de finalidades emancipatórias, depende a priori do estabelecimento de novas estratégias de organização curricular - menos prescritivas, por exemplo - que sejam capazes de envolver os sujeitos de forma a que estes se assumam como autores. Argumenta que, além das forças de poder com suas prescrições, é importante que nos reconheçamos como sujeitos envolvidos diretamente em todo tipo de processo social e que, como sujeitos, deixemos nossas marcas nesses processos (Goodson, 2007) 4

Tensiono essa concepção na medida em que entendo que a atuação de sujeitos nos mais diversos processos sociais é independente de qualquer apelo que, como estratégia política, pretenda a consecução de um determinado projeto curricular. Essas ações estão presentes, como diferenças, nos processos que envolvem articulações para a hegemonização de propostas curriculares - emancipatórias ou não. Defendo que não se pode 
essencializar o sujeito como forma de "prepará-lo" para atuar na consecução de um projeto estabelecido a priori, argumentando que as concepções de "um sujeito centrado, sujeito vanguardista, capaz de determinar e decidir" - como no currículo narrativo - ou "a concepção de um sujeito-sujeitado pelas estruturas e determinado por estas" (De Alba, 2007, p. 84) - concepção embutida na teoria do contexto - são concepções que, no modelo teóricometodológico sugerido neste trabalho, precisam ser superadas.

O segundo conceito que indico como lacuna a ser superada no modelo analítico de Goodson é o de conhecimento. Na HDE, o conhecimento adquire centralidade, na medida em que se propõe que sua disciplinarização "funciona como tecnologia de organização e controle da própria escola" e da academia e, dessa forma, imbrica-se "na compreensão de cultura marcada por categorizações do conhecimento científico" (Lopes \& Macedo, 2011b). Em trabalhos recentes, Lopes e Macedo (2011a) vêm buscando compreender as práticas contextuais que acabam por legitimar determinados conhecimentos, questionando "as perspectivas axiológicas de análise do conhecimento escolar [e acadêmico] que têm por padrão as definições do conhecimento científico" (Lopes \& Macedo, 2011b), como pensado por Goodson. Tendo a defender, em diálogo com essas autoras, a concepção de que os conhecimentos disciplinares não podem ser entendidos como "repertório estável" (idem), e o processo de seleção que acompanha a definição desses conhecimentos não pode ser entendido a partir da essencialização dos sujeitos que operam nesse processo, quaisquer que sejam as identidades que se busque fixar, como, por exemplo, no modelo de Goodson, aquela que constitui as comunidades disciplinares, a partir dos saberes disciplinares que dominam. Lopes \& Macedo (2011a) entendem que, mesmo nas concepções curriculares que operam com o conceito de currículo como prática, permanece a ideia de "que há um saber externo à escola para ser transmitido via currículo (...) e a cultura permanece sendo tratada como objeto de ensino" (2011, p. 101). O conhecimento se apresenta, dessa forma, reificado e a escola é o local da sua transmissão.

Busco superar a concepção de conhecimento em Goodson, argumentando com a impossibilidade desse repertório e tensionando a ideia de seleção. Os processos que resultam nas escolhas são processos de significação, definidos por sujeitos que se constituem e constituem o que 
selecionam nas arenas políticas como sendo os melhores. Dessa forma, sujeitos, saberes e conhecimentos são constituídos na luta política que se trava no sentido de garantir a legitimação de um determinado projeto curricular.

Assim, no sentido de superar as lacunas que o modelo analítico da HDE apresenta, entendo a Teoria do Discurso (TD) de Ernesto Laclau (1993, 2005, 2006) como capaz de oferecer ferramentas mais sólidas para a compreensão das políticas curriculares. Apresento, na seção a seguir, as categorias de análise que me permitem, a partir da ressignificação da HDE, delinear a postura epistêmica que adoto.

\subsection{A análise da micropolítica disciplinar pela Teoria do Discurso}

Destaco inicialmente a possibilidade, na Teoria do Discurso, de compreensão de política curricular como discurso, e deste como uma estrutura descentrada que permite colocar em destaque os processos articulatórios que visam à hegemonia de um determinado sentido nas políticas. Enquanto estrutura descentrada, apenas provisória e contingencialmente se delimita um centro capaz de aglutinar os diferentes sentidos postos em disputa, colocando em xeque a dicotomia ação-estrutura, na medida em que esse fechamento nunca é pleno nem implica na possibilidade de fechamento total da significação. Com essa concepção é possível reduzir a ênfase que as análises de políticas curriculares conferem à subordinação das políticas ao macrocontexto, quer este esteja referido ao Estado, ao mercado ou ainda à sua interconexão.

Os sentidos que essas instâncias pretendem hegemônicos entram também na disputa por hegemonia, na forma de demandas a serem negociadas, do mesmo modo que os sentidos disciplinares também se apresentam em disputa. Mas, tanto uns quanto outros, ao serem articulados, passam por processos que recontextualizam por hibridismo (Lopes, 2007) os sentidos postos em disputa. Neste movimento, perdem parte de seus sentidos "originais" e transformam-se em momentos da articulação. Em outras palavras: esses elementos passam a ser apenas elementos da cadeia articulatória que se estabelece visando à hegemonização de determinado projeto curricular. 
Para a TD, os significados dos elementos são definidos em meio a processos articulatórios e não a priori, enfatizando-se a dimensão da significação, o caráter constitutivo da realidade e, sobretudo, o conceito de política, tornando central a questão do poder como constituidor de relações sociais (Burity, 2008). Assim, mesmo aceitando, em Goodson, a ideia da importância da atuação das comunidades disciplinares na definição das políticas curriculares, torna-se necessário entender que, enquanto grupos sociais particulares, essas comunidades defendem ou representam determinados elementos diferenciais na cadeia de sentidos postos em disputa, na forma de demandas (Laclau, 2006), e que essas demandas precisam se fazer equivaler as outras demandas presentes nos processos articulatórios e que, nesse processo, se hibridizam.

As comunidades disciplinares, em Goodson, incluem um grupo social extenso e portador de uma identidade fixa, determinada pelos saberes e conhecimentos que dominam. Argumento que nem todos os membros dessas comunidades são chamados a produzir os textos que têm a pretensão de funcionar como norteadores das políticas curriculares e que, na cadeia articulatória que se estabelece no sentido da hegemonização de um determinado projeto curricular, sentidos se metamorfoseiam, isto é, entram na cadeia de significação com sentidos distintos do que, em outro sistema ou totalidade, significam. Laclau denomina esses sentidos de 'significante flutuante', defendendo que, em um plano conceitual, teórico, um mesmo significante pode assumir distintos significados e, em determinadas situações, até significados contraditórios ou antagônicos em função do discurso em que se inscrevem, prestando-se "a manejos pouco rigorosos [e propiciando] confusões de maneira intencional ou não intencional" (De Alba, 2007, p. 47). É que, para ter a função de representação universal, as demandas precisam despojar-se de conteúdos precisos e concretos ou, em outras palavras, têm que se esvaziar de sua relação com significados específicos para se transformar em um significante esvaziado de sua referência direta a um determinado significado. Laclau denomina esse universal que, provisória e contingencialmente, reúne a diversidade de sentidos particulares, de 'significante vazio': termo vago e impreciso o bastante para representar a totalidade de elementos heterogêneos (Laclau, 2006, p. 25), mas necessário ao processo de hegemonização. 
Para Laclau, a constituição de um discurso hegemônico obedece, então, a duas lógicas: a da diferença e a da equivalência. Por lógica da diferença compreende a configuração de um sistema ou totalidade que se "constitui por elementos diferenciais que em movimento relacional se articulam para bloquear parte de sua identidade diferencial e conformar uma identidade mais ampla" (De Alba, 2007:58). Por lógica de equivalência "se refere à capacidade de uma prática política articulatória relacionar múltiplas (...) identidades diferenciais em uma identidade nova" (idem, p. 59). Hegemonia, então, é uma relação em que uma determinada identidade, em uma determinada cadeia discursiva, de forma precária e contingente, passa a representar, a partir de uma relação equivalencial, múltiplos elementos.

Nos processos hegemônicos, todas as identidades se constituem sempre de forma incompleta, seja em função da sua própria articulação incompleta de sentidos, seja a partir de sua relação com outras identidades, seja, ainda, por sua negação a partir de seu corte antagônico (Mendonça \& Rodrigues, 2008, p. 30). Por antagonismo, Laclau entende a delimitação de uma fronteira política (Laclau, 2006, p. 23) que coloca no exterior da cadeia de demandas um elemento dela excluído, mas que é capaz de aglutinar, em torno de si, as diferenças postas em disputa. Nesse sentido, discursos hegemônicos são discursos sistematizadores e aglutinadores em torno de um ponto nodal: são discursos de unidade, mas unidade de diferenças (Mendonça \& Rodrigues, 2008, p. 29).

Trata-se de um processo de universalização do particular (idem, p. 48), que pode ser interrompido por uma ação, por um confronto com outros discursos totalizadores ou por incapacidade de as próprias diferenças articuladas manterem a lógica articulatória. É preciso considerar que a lógica articulatória hegemonizada constitui novos sujeitos que, envolvidos por uma dimensão de afeto, por cargas pulsionais que não se resumem a carências materiais dadas ou a um denominador comum a todos os sujeitos interpelados por outro discurso, tornam contingente e precária a hegemonia alcançada (Burity, 2008, p. 48).

No processo de hegemonização é preciso que se considere as representações nele envolvidas. Para a Teoria do Discurso, um texto político só pode representar a política se seus sentidos forem compreendidos como parte de uma dada articulação hegemônica e, dessa forma, forem capazes de 
fixar determinados sentidos às leituras. Mas essa fixação, devido à impossibilidade de finitude da significação, só se torna possível se, em um dado momento e em relação a um antagonismo, um dos sentidos se converter em ponto nodal capaz de articular as diferenças de sentidos postas em disputa. Torna-se necessário também que um significante assuma a função de significar o sistema, a totalidade, isto é, um significante capaz de anular as diferenças em disputa.

A concepção de sujeito na TD oferece também maiores possibilidades de análise na perspectiva curricular que defendo, ao propor o entendimento do sujeito como a distância entre uma estrutura indecidível - no sentido de que seu fechamento, sempre provisório e contingente, depende de articulações que visam a estabelecer, entre diferentes "posições de sujeitos", cadeias que ora fazem equivaler ora fazem diferir as diferenças que carregam - e o momento da decisão. Para Laclau, o sujeito é ausência, falta, carência, na medida em que no momento da decisão operam mecanismos de seleção e de exclusão, e essas exclusões constituem também o sujeito (Laclau, 1993).

Ao conferir centralidade à dimensão da significação, a TD potencializa o político, superando a concepção de que os sujeitos que atuam na luta política são portadores de algum grau de essencialismo que os determina. Se, com Goodson (1997), posso defender a ausência de sentidos estritamente epistemológicos na constituição das disciplinas em busca de status, recursos e território, com Laclau (2006) posso compreender as lutas políticas travadas por múltiplos sujeitos com vistas à hegemonização de determinado projeto curricular. Os sentidos de natureza epistemológica são apenas elementos de uma cadeia de diferenças articuladas: são particularismos, que a partir de uma relação equivalencial transformam-se em elementos-momentos, isto é, em discursos hegemônicos que aglutinam e sistematizam sentidos diversos em relação à articulação estabelecida.

Para que possamos entender o que Laclau define como relação de equivalência, é preciso aceitar a ideia de que as formações sociais atuais, longe de se constituírem como algo essencialmente dado (Laclau, 2006, p. 21), precisam ser analisadas tomando como base a ideia da dispersão de posições de diferentes sujeitos. É a partir dessa dispersão de antagonismos e de diferentes significações que se pode, primeiro, compreender os processos de articulação que acabam por hibridizar textos e discursos no sentido de fixar 
sentidos para as políticas curriculares. Segundo, compreender, como em meio a processos articulatórios, alguns significantes são privilegiados, constituindo os pontos nodais em torno dos quais se estabelece, de forma provisória e contingente, a hegemonia de uma determinada concepção. Por fim, compreender a delimitação de uma fronteira política (idem, p. 23) que coloca em seu exterior um elemento excluído da cadeia, mas que a ela pertence e que aglutina, em torno de si, as diferenças postas em disputa.

O fechamento da cadeia de equivalência em torno de pontos nodais e dos significantes vazios, no intuito de hegemonizar um dado projeto curricular, depende de processos de condensação e de deslocamento e pode ser entendido a partir da analogia com processos de constituição da linguagem escrita ou falada. Assim, no processo de fechamento da cadeia de equivalência, um significante aglutina/condensa diferentes sentidos significante vazio no modelo de Laclau -, tratando-se, portanto, de processos metafóricos. Simultaneamente, um particularismo se desloca, transformandose em um universalismo que, de forma contingente e provisória, se hegemoniza, representando a dispersão que as diferenças carregam. Nesse caso, estamos diante de processos metonímicos, estendendo a analogia com a linguagem. Compreender os sentidos que vão sendo hegemonizados na política curricular implica, portanto, entender as metáforas que condensam sentidos em um único significante e permitem que um particular seja metonimicamente alçado à categoria de universal (Laclau, 2005).

Essas são, portanto, as bases teóricas que alicerçam o modelo analítico que busco construir. Apresento, na seção seguinte, o percurso metodológico que adoto, chamando a atenção para o fato de que se trata apenas de uma possibilidade de estratégia de pesquisa, dependente de novas reconfigurações teórico-metodológicas que se compatibilizem com as especificidades de novos objetos a serem investigados.

\section{Brasil, anos de 1980: a micropolítica da disciplina História}

Várias são as fontes a que se pode recorrer a fim de identificar e compreender a lógica de articulação que permitiu que diferentes sentidos se condensassem em torno da extinção da disciplina Estudos Sociais. Desse 
quadro empírico de possibilidades, selecionei, para este artigo, a análise dos textos editados na Revista Brasileira de História ( $\mathrm{RBH})$, que me permitiu, ao lado de outros trabalhos de investigação do campo curricular, apresentar, nesta seção, a delimitação do tema e as concepções teórico-metodológicas com as quais abordo o objeto de investigação selecionado.

Justifico essa escolha pelo fato de que toda a coletânea da $\mathrm{RBH}$ encontra-se digitalizada e disponível no site da Associação Nacional de História (ANPUH). As edições da revista reunem "artigos originais e afinados com o avanço da produção historiográfica contemporânea, visando atuar como um veículo de divulgação das práticas de pesquisa, escrita e ensino da História" (RBH, s/d). Entretanto, mais do que meio de divulgar essas práticas, considerei os artigos como representações que me possibilitaram identificar e compreender a lógica de articulação que permitiu que diferentes sentidos se tornassem equivalentes, com vistas à extinção da disciplina Estudos Sociais. $\mathrm{Na}$ análise dos textos divulgados nas edições selecionadas da $\mathrm{RBH}$ identifiquei os sentidos que, alçados a um caráter universal, contingente e provisório, permitiram que a disciplina História mantivesse o status ameaçado ao longo dos anos de 1980.

O primeiro número da $\mathrm{RBH}$ foi publicado em março de 1981, tendo como finalidade a divulgação de trabalhos na área de História, antes restrita aos Anais do Simpósio Nacional de História que, até então, cumpria essa tarefa. Com um acervo de 62 edições disponibilizado no portal Scielo (a partir do volume $17, \mathrm{n}^{\circ} 34$, de 1997) e no site da ANPUH (todo o acervo), a RBH veicula conteúdos de uma rede de pesquisadores dedicados às diferentes áreas do conhecimento histórico ( $\mathrm{RBH}$, v. 28, n 56$)$. No último número, a RBH "inaugurou uma nova fase com a edição exclusivamente digital e também com sua versão em inglês" (RBH, v. 30, n 59). Na década de 1980 foram editados 19 números da RBH. Neles estão disponibilizados 145 artigos e 59 resenhas, além de uma seção reunindo notícias, sobretudo das atividades dos núcleos regionais da ANPUH. A partir da edição de $n^{\circ} 6$, passou a ser apresentada organizando artigos e resenhas por eixos temáticos.

A RBH é uma publicação da ANPUH, identificada nesta pesquisa como a comunidade disciplinar de História. A fundação dessa associação, em 1961, teve (tem ainda) como finalidades "representar a comunidade dos profissionais de História perante instâncias administrativas, legislativas, 
órgãos financiadores e planejadores, entidades científicas ou académicas" (Estatuto da ANPUH, art. $4^{\circ}$ ). As finalidades da ANPUH, estatutariamente definidas, tensionaram as finalidades que os órgãos centrais do Estado brasileiro pretendiam hegemonizar em direção ao que, ao longo da década de 1960, se convencionou chamar política da segurança nacional e de desenvolvimentismo econômico.

No âmbito das propostas curriculares, ao longo das três primeiras décadas de fundação da ANPUH, o estabelecimento de estratégias em diferentes campos discursivos colocou em disputa as finalidades disciplinares da História. Os campos discursivos de influência e de produção de textos curriculares representaram na Lei 4.024/61 (Diretrizes e Bases da Educação Nacional) e, dez anos mais tarde, na Lei 5.692/71 e no Parecer 853/71, a instituição da disciplina Estudos Sociais em substituição à História e à Geografia. De igual modo, fizeram aligeirar, nas universidades, a formação dos professores com a criação das licenciaturas curtas em Estudos Sociais.

A ideia da criação da disciplina Estudos Sociais não era nova. Desde as primeiras décadas do século $\mathrm{XX}$, difundiam-se concepções curriculares que, inspiradas em John Dewey e nas propostas curriculares americanas, dirigiam críticas ao distanciamento da escola em relação à realidade. Defendiam que "a escola deveria se preparar para enfrentar a sociedade moderna, tendo como doutrina a democracia, pautada na solidariedade social, no espírito de cooperação e na construção de um ambiente dinâmico de conexão com a região e a comunidade" (Fernandes, 2008, p. 2). As estratégias adequadas ao enfrentamento da temática "realidade brasileira" significante esvaziado de um sentido fixo - possibilitaram, também, condensar diferentes sentidos neste significante, de tal modo que, em torno desse processo de condensação de sentidos, as diferenças se fizessem equivaler com vistas à hegemonização do projeto curricular que defendiam e/ou representavam os sujeitos reunidos em torno da comunidade disciplinar de História ou das instâncias governamentais.

A proposição de uma nova disciplina - Estudos Sociais - foi defendida, sobretudo pelo campo discursivo de influência, como possibilidade de consecução da compreensão da realidade nacional - finalidade educacional prescrita nos documentos oficiais -, antagonizando-se à concepção de que a compreensão da realidade brasileira dependia da manutenção da História nos 
currículos, defendida nos fóruns da ANPUH como a disciplina formadora "do aluno, quer dizer, [aquela] que o torna mais livre, mais capaz de conhecer, compreender e escolher por ele mesmo, já que a base do método é a autonomia intelectual" (RBH, v. 2. $\left.n^{\circ} 3\right)$. Argumentando que "as disciplinas especiais [História, Geografia, Antropologia, Sociologia] são produtos do pensamento, de pesquisa, (...) que resultam de estudos científicos, desinteressados e elevados" e que o objetivo da nova disciplina era "o ensino, a vulgarização", a ela não cabendo "o propósito de fazer progredir a ciência, mas educar" ( $\mathrm{RBH}$, v. 2, n 4, p. 121), pesquisa e ensino, teoria e prática e, sobretudo, conhecimentos de natureza historiográfica e conhecimentos do campo curricular tensionaram-se.

Os micro-contextos de influência e de produção de textos, no âmbito das universidades e escolas, apropriaram-se das determinações legais, estabelecendo propostas curriculares que, embora adotando a nova disciplina como componente curricular, mantinham as disciplinas História e Geografia enquanto seleção de conteúdos e finalidades disciplinares ${ }^{5}$. Essas situações me permitem ratificar a concepção que defendo, com Ball $(1989,1998)$, de que as políticas curriculares não podem ser analisadas, exclusivamente, na perspectiva das teorias estadocêntricas: processos articulatórios em relações não verticalizadas de poder (García Canclini, 2008) fazem imbricar o macro e o micro contextos, dando lugar a propostas híbridas que reconfiguram os sentidos representados nos textos das políticas.

A instituição da nova disciplina escolar e a criação das licenciaturas curtas em Estudos Sociais, nas universidades, constituíram-se na "concretização da maior ameaça enfrentada pela História e pela Geografia, desde a sua instituição como disciplinas científicas autônomas e específicas" $\left(\mathrm{RBH}, \mathrm{v} .2, \mathrm{n}^{\circ} 4\right.$, p. 118), ameaça que desencadeou o estabelecimento de um conjunto de ações políticas que delimitaram outros lugares de poder não circunscritos ao macro-contexto de influência, mas que esteve circunscrito a todas as arenas políticas por onde circulavam as políticas.

Diferenças em relação aos sentidos das políticas curriculares para o ensino da disciplina História nas escolas, nas universidades e nas instâncias oficiais de definição das políticas entraram em disputa, trazendo para o centro dos debates demandas relativamente: à organização disciplinar e departamental dos currículos de formação de professores; ao distanciamento 
entre as propostas de ensino e a formação docente nos cursos de licenciatura; à ênfase na História episódica e factual, na causalidade, na sucessão linear e na neutralidade científica; e à importância dos métodos da pesquisa historiográfica como componente curricular. Demandas diversas, naquele contexto, acabaram por se equivaler em torno de um exterior constitutivo capaz de articulá-las. Em outras palavras: a disciplina Estudos Sociais, instituída pela Lei 5.692/71, representou o antagonismo capaz de condensar diferentes sentidos postos em disputa, sem que isso significasse conferir sentidos fixos para as diferentes demandas articuladas na cadeia de equivalência.

Ao longo das décadas de 1960 a 1980, a disciplina História vinha sendo duramente desestabilizada, face aos avanços do estruturalismo de Claude Lévi-Strauss (2005). A ênfase nos fatores políticos, nas grandes personalidades e na cronologia, bem como no protagonismo da História no âmbito das Ciências Sociais, pressupostos que, dentre outros, orientavam até então as pesquisas em História, foram postos em xeque. Para o antropólogo e etnólogo francês, "a História estaria fadada a uma função propedêutica, fornecendo para as pesquisas sua narrativa cronológica", na medida em que seus pressupostos teóricos forneciam, apenas, segundo o autor, "dados de investigações relativos à superfície gratuita dos acontecimentos" (Rodrigues, 2009, p. 170) que pouco contribuíam para o conceito de estrutura, fundamental na compreensão do estruturalismo. No centro dos debates do campo historiográfico, os estudos realizados pelo grupo da Escola dos Annales - a Nova História - criaram, ao longo de duas décadas, uma cadeia que se unia tendo como ênfase a crítica à História tradicional de marcas positivistas, ao mesmo tempo em que buscava recuperar o protagonismo da História no campo das Ciências Sociais.

A manutenção da disciplina História nos currículos escolares e acadêmicos, como pretendia a comunidade disciplinar de História, ou sua fusão na nova disciplina Estudos Sociais, como pretendia, dentre outras instâncias, a política dos órgãos centrais, tensionou-se e foi negociada em processos articulatórios aos quais se aliaram outros sujeitos reunidos em torno da Associação dos Geógrafos Brasileiros (AGB) e da Associação Nacional de Pós-graduação em Educação (ANPED). O questionamento à política educacional e à função social da escola e do processo educativo 
(Mesquita, 2008) e os embates travados no campo da historiografia e da Teoria da História estenderam os processos articulatórios visando a possibilitar, em torno de sentidos provisoriamente comuns, o estabelecimento da hegemonia do projeto que defendia ou representava cada um desses grupos sociais.

Pesquisas recentes tendem a aceitar a ideia de que a discussão em torno da disciplina Estudos Sociais não se alicerçou em termos de argumentos de caráter exclusivamente epistemológico, mas remontou "à preocupação dos associados com a demanda de mercado de trabalho do historiador e às investidas do MEC em relação ao campo da formação profissional" (Martins, 2002). Outras pesquisas (Mesquita, 2008) chamam a atenção para o fato de que o espaço para as discussões que pudessem argumentar epistemologicamente em defesa da importância da disciplina História nos currículos foi bastante reduzido (idem, p. 80) no campo discursivo dos fóruns da comunidade disciplinar de História.

Considero importante afirmar que, embora a ameaça representada pela instituição da nova disciplina tenha se convertido no antagonismo que possibilitou a formação de uma cadeia de equivalência necessária - na perspectiva que defendo - para a recuperação do status da disciplina História, diferentes demandas estiveram em disputa. Uma cadeia de diferenças com relação aos sentidos que defendiam ou representavam determinados grupos no interior da ANPUH se manifestou. Um grupo de associados - o núcleo de historiadores-pesquisadores ${ }^{6}$ - enfrentou "a ameaça" com o fortalecimento da pesquisa e da divulgação historiográfica, ocupando posição de destaque, por exemplo, no espaço da diagramação da $\mathrm{RBH}$, bem como, quantitativamente, os textos que produziam eram editados em maior número. Outro grupo - o núcleo de historiadores-professores ${ }^{7}$-, preocupado com o ensino da disciplina nas universidades e nas escolas, ocupou o espaço da seção de noticiários, e os textos que editava apareciam em número reduzido nas edições da $\mathrm{RBH}$. Mais do que tomar como definitiva a classificação apresentada acima, tomo-a aceitando a concepção de comunidade disciplinar, não como um grupo de sujeitos portadores de uma identidade fixa, mas como um grupo social que se define em processos articulatórios de identificação, contingentes e provisórios. 
Com relação às licenciaturas curtas, essas, na década de 1980, depois de avaliadas em relatórios enviados ao MEC e de cuja elaboração participou a comunidade disciplinar de História, foram substituídas pelas licenciaturas plenas. O Conselho Federal de Educação (CFE), tendo como relator o conselheiro Paulo Nathanael Pereira de Souza, emitiu Parecer, alegando "que a curta duração da licenciatura [resultara] na graduação deficiente do professor (...) não apenas dos conteúdos de conhecimento, como ainda das técnicas pedagógicas ligadas ao ensino de atividades e áreas de estudo" $\left(\mathrm{RBH}, \mathrm{v} .2, \mathrm{n}^{\circ} 4\right.$, p. 120). O diagnóstico, em relação às licenciaturas curtas, serviu, no Parecer, não como justificativa para a extinção da disciplina Estudos Sociais, mas como justificativa para a criação das licenciaturas plenas em Estudos Sociais, transferindo o ônus das críticas para o processo de profissionalização docente.

A fim de ser implementado nas Universidades no ano de 1981, esboçou-se um Projeto de Resolução fixando-se um currículo mínimo para os cursos de licenciatura plena em Estudos Sociais. Desse currículo mínimo constava um grupo de matérias comuns a todas as habilitações, denominadas matérias básicas (Fundamentos das Ciências Sociais, Sociologia, Antropologia Cultural e Técnicas de Pesquisa Social); matérias específicas por habilitação (História, Geografia, Educação Moral e Cívica e Organização Social e Política do Brasil), matérias obrigatórias (Educação Física e Estudo de Problemas Brasileiros), além das matérias pedagógicas (Filosofia e Psicologia da Educação, Didática, Estrutura e Funcionamento do Ensino de $1^{\circ}$ e $2^{\circ}$ graus, Prática de Ensino de $1^{\circ}$ e $2^{\circ}$ graus e Estágio Supervisionado). A análise desta nova grade curricular evidenciou: a perda do protagonismo da História para outras disciplinas do campo das Ciências Sociais, conferindo à História e à Geografia o caráter de habilitações; a priorização dos fundamentos gerais das Ciências Sociais, ratificando a tendência da hegemonização do estruturalismo e abandonando a metodologia própria da pesquisa histórica; e, por fim, a separação, nas propostas curriculares, das disciplinas pedagógicas e aquelas ligadas ao conhecimento histórico.

Criticando "os conteúdos programáticos da matéria [que] não chegam a ganhar congruência e unidade, permanecendo como uma espécie de colcha de retalhos" e criticando os professores que não "chegaram a firmar no cenário do magistério um perfil psicográfico"8 aceitável (RBH, v. 2, nº 4 , p. 
119), a Resolução do CFE, de setembro de 1980, provocou uma série de reações: "as associações científicas e a comunidade acadêmica mobilizaram, em todo o território nacional, [entendendo-a] como danosa ao conhecimento científico e ao ensino" (RBH, v. 2, n 4, p. 117). Ações contrárias ao Parecer do CFE foram planejadas nos núcleos da comunidade disciplinar de História em vários estados da federação, envolvendo os professores da escola básica, a "maior reserva de mercado de trabalho do historiador" (Mesquita, 2008, p. 71), que passaram a ser admitidos como membros do quadro de associados. $A$ ANPUH desenvolveu "uma campanha em âmbito nacional, reafirmando a exclusiva competência da comunidade universitária, para decidir sobre a natureza de sua produção científica e o conteúdo da formação dos profissionais de Geografia e História" (RBH, v. 1, n 1) e o CFE retirou o Projeto de Resolução que pretendia instituir a licenciatura plena em Estudos Sociais.

A análise realizada me permitiu concluir que os sentidos atribuídos pelos diferentes sujeitos que atuavam na comunidade disciplinar de História e representados nos textos da $\mathrm{RBH}$ carregavam diferenças. Diferiam com relação ao que entendiam ser a melhor formação para os professores de História, com relação ao que entendiam ser o melhor ensino de História nas universidades e nas escolas e, dentre outras, sobre o que entendiam ser o entrosamento entre as disciplinas de referência e as disciplinas pedagógicas. Estabeleceram consensos no que entendiam por teoria e prática, concordando no seu caráter indissociável, aproximaram-se na importância da validação epistemológica do que se ensinava nas escolas, na importância da pesquisa histórica como componente curricular, dentre outros. Por fim, aglutinaram as diferenças que carregavam em torno de um projeto que pretendia a extinção da disciplina Estudos Sociais. Fizeram equivaler as diferenças, entendendo a História como a disciplina formadora do aluno, portanto com possibilidade de atender ao que prescreviam os textos que representavam as políticas do campo discursivo de influência, isto é, o conhecimento da realidade brasileira - finalidade vaga o suficiente para ser capaz de aglutinar diferenças com relação ao que seja um melhor ensino da História e uma formação profissional mais adequada.

Ao longo dos anos de 1980, a disciplina Estudos Sociais permaneceu no rol das disciplinas escolar e acadêmica, sendo definitivamente extinta nas escolas e universidades quando foram editados os Parâmetros Curriculares Nacionais, em 1997. 


\section{Concluindo com novas questões: a junção da História e da Geografia em Portugal, nos anos iniciais do século XXI}

As teses que enunciei não têm a pretensão de serem tomadas como representativas de um conjunto de políticas curriculares. Defendidas em dezembro de 2010, essas teses voltam a ocupar o foco da minha atenção ao tomar conhecimento: (a) do Decreto-Lei n 43/2007 que, em Portugal, aprova o regime jurídico da habilitação profissional para a docência na Educação PréEscolar e nos Ensinos Básico e Secundário, estabelecendo como domínio de habilitação para a docência a junção das disciplinas História e Geografia; e (b) de um campo de tensão expresso em um conjunto de documentos assinados pela comunidade disciplinar de História e de Geografia ${ }^{9}$. As primeiras indagações nasceram, portanto, da leitura desses textos: a que finalidades atende a institucionalização desse domínio de habilitação?; como a comunidade disciplinar de História o compreende?; e que sentidos estão postos em disputa?

Encontrar respostas a essas questões exige um esforço investigativo ainda a empreender. Entretanto, creio ser possível definir, preliminarmente, no que De Alba (2007) nomeia como trajeto metodológico de pesquisa, a delimitação do tema e uma concepção teórica para a sua abordagem. Com relação a essa última, apresentei-a na primeira seção deste texto. Minha intenção é, a título de considerações finais, elencar algumas questões que, considerando a concepção de currículo como política cultural e a potência dos aportes teórico-metodológicos da Teoria do Discurso, surgem da delimitação dessa temática, circunscrevendo-a aos sentidos que vêm sendo atribuídos à profissionalização docente e como, nesse particular, se apresenta a tensão entre conhecimento de referência e conhecimento pedagógico.

Com relação aos textos curriculares lidos, detive-me na análise do Decreto 43/2007, do Manifesto "História, democracia e desenvolvimento" de maio de 2010, em favor do ensino de História, da Petição Pública Nacional a ser encaminhada à Assembleia da República e das conversas que mantive com Luís Grosso Correia (Professor Doutor da Faculdade de Letras da Universidade do Porto), Isabel Barca (Professora Doutora da Universidade do Minho) e Raquel Pereira Henriques (Professora Doutora da Universidade Nova de Lisboa e presidente da Associação de Professores de História $\mathrm{APH})$, aos quais, aproveitando a escrita desse trabalho, agradeço a gentileza 
com que me receberam quando do meu estágio de doutoramento na Universidade do Porto (março-junho de 2011).

Essas fontes representam uma parcela mínima do acervo que me foi possível recolher. Dele fazem parte um conjunto de documentos que, desde a publicação do Decreto-Lei $n^{\circ} 74 / 2006$, que implementou, em Portugal, o Processo de Bolonha, vêm sendo editados. Dele também faz parte um conjunto de publicações que compõe o arquivo da APH. As produções da Academia Portuguesa de História - ainda não analisadas - também se constituiriam em material empírico relevante, na medida em que, considerando as finalidades a que se propõe, decerto mantém, em seu acervo, material de análise relevante para esta investigação, mesmo que seja para configurar, como depoimento colhido, seu silenciamento em relação às "ações que se manifestam contrariamente ao projeto de junção das duas disciplinas" nos currículos de formação docente (depoimento, 2011).

No Decreto 43/2007, a prioridade das políticas é a superação dos "défices de qualificação portuguesa" que, dentre outras ações, depende da qualificação dos educadores e professores. Essa, no contexto do Processo de Bolonha, deve ser o "mestrado, (...) com vista a reforçar a qualidade da sua preparação e a valorização do respectivo estatuto sócio-profissional". A profissionalização docente como condição para que se alcance as metas educacionais - combate ao insucesso escolar e ampliação do acesso aos estudantes do nível secundário - vem, dentre as ações, adquirindo centralidade. Os textos oficiais sugerem, no sentido da consecução dessas metas - nesse particular, o Mestrado de Ensino em História e Geografia é um exemplo -, diluir a tensão entre o conhecimento disciplinar e as disciplinas pedagógicas, conferindo ao conhecimento científico e acadêmico de referência a supremacia na interconexão entre a formação e o exercício da docência.

A discussão em torno dessa tensão ganha centralidade na preocupação das instituições de Ensino Superior, ao avaliarem "os modos como estão a ser concretizados os princípios e as orientações preconizadas para a formação" (Fernandes, 2009, p. 161). Por um lado, verifica-se a defesa de que a profissionalização docente "é menos uma questão de saber científico e muito mais uma questão de ordem pedagógica" (idem, p. 167), e, por outro, "a preocupação com a perda de estatuto do conhecimento, nomeadamente 
quando a focagem ocorre em função das competências" (idem, p. 172). Ambas, como sugere Fernandes (2009), são "olhares diversos para um debate útil".

O debate não se trava, entretanto, apenas no campo das Ciências da Educação como o que acima fiz menção. Na cadeia articulatória, demandas curriculares da comunidade disciplinar de História fundamentam-se no fato de que o "modelo de formação inicial é atentatório da dignidade das disciplinas de História e do próprio ensino, mais em geral" (Petição Pública, 2010), estendendo a tensão entre os dois conhecimentos. Argumentam com a impossibilidade de uma habilitação de qualidade em um modelo curricular que forma para a docência indiscriminada nas duas disciplinas para o ensino do $3^{\circ}$ Ciclo da Educação Básica e do Secundário. Argumentam, também, que o modelo em vigor, que substituiu o anterior, no qual a formação na área científica de referência - História ou Geografia - se estendia por um período de 3 a 4 anos, vem sendo duramente atacado, na medida em que se reduziu para 1 ou 2 anos. O que se deseja é que "a habilitação profissional para a disciplina de História passe a ser concedida pelo Grau de Mestre em Ensino de História" (idem), garantindo-se uma formação mais concentrada no campo da História.

Sem contrariar uma organização curricular em torno das competências, os signatários do Manifesto e da Petição Pública Nacional entendem que "a História pode contribuir para a promoção de competências, gerais, transversais e específicas (...); pode facilitar o contato com instrumentos de análise que potenciam o combate às assimetrias socioculturais e garantir uma base sólida" (idem) para a inserção nos mais variados postos de trabalhos, finalidades que não contrariam o que se estabelece no decreto-lei.

Não trato a comunidade disciplinar como portadora de uma identidade fixa a partir dos conhecimentos que domina. Nela, diferenças se apresentam e se articulam - não necessariamente de caráter epistemológico - em busca da hegemonia de diferentes sentidos para as políticas. Em processos articulatórios agregam-se outros atores, como é o caso da comunidade disciplinar de Geografia representada pela Associação Portuguesa de Geógrafos. Outras diferenças apresentam-se "fora" da cadeia articulatória como a da Academia Portuguesa de História, que não assinou, até o presente, 
a Petição a ser encaminhada à Assembleia da República - por a interpretarem como de "caráter corporativo" ou por entenderem, no caso dos Departamentos de História de algumas universidades, que "o papel das universidades seria apenas o da produção do conhecimento no campo historiográfico e da teoria da História" (depoimento, 2011).

Dessa delimitação do tema advém uma série de questões. Entendendo que, na perspectiva da Teoria do Discurso, o processo de hegemonização das políticas curriculares implica uma cadeia de sentidos que flutuam (significante flutuante), mas que carecem de que um deles, de forma precária e contingente, assuma a função de aglutinar as diferenças expressas nessa cadeia (significante vazio), algumas questões podem servir de orientação a novas pesquisas. Dentre essas questões indico: (a) que sentidos são atribuídos ao significante profissionalização docente nos textos das políticas?; (b) que sentidos se apresentam no quadro reformador que acompanha a edição do DL 43/2007?; (c) que sentidos correspondem a tradições/intimações defendidas pela comunidade disciplinar de História?; (d) que ressignificações e novos usos são atribuídos a essas intimações?; (e) que antagonismo possibilita a criação de uma cadeia de equivalência, responsável pela hegemonização da junção das duas disciplinas nos currículos escolares e universitários?

Uma análise futura pode vir a ser potente na compreensão do projeto curricular que possibilitou, em Portugal nos anos iniciais do século XXI, a junção das duas disciplinas, a partir do Decreto $n^{\circ} 43 / 2007$. Entretanto 0 fechamento discursivo que possibilitou a hegemonia dos Mestrados em Ensino de Geografia e Ensino de História para a profissionalização docente, decerto se deu às custas do apagamento, provisório e contingente, de diferenças que ora reacendem o debate e originam novas ações políticas. É nesse terreno de antagonismos que se pode pensar na manutenção ou na mudança do que hoje se apresenta como hegemônico, e é nessa perspectiva que se pode empreender um processo investigativo das políticas curriculares com relação à ampliação da perda do status da disciplina História, em Portugal. 


\section{Notas}

1 Os resultados dessa pesquisa estão apresentados em Lopes, Dias, e Abreu (2011). Originaram também uma comunicação aprovada para ser apresentada na $34^{a}$ Reunião da ANPEd (Oliveira, 2011b).

2 Neste artigo amplio o texto da comunicação aprovada para publicação nas Actas do XI Congresso da Sociedade de Psicologia e Ciências da Educação (Oliveira, 2011b).

3 Grupo de pesquisa do Programa de Pós-graduação em Educação da Universidade do Estado do Rio de Janeiro (PROPEd-UERJ), coordenado pela Profa. Dra. Alice Casimiro Lopes.

4 Goodson (2007) denomina essa constituição curricular de 'currículo narrativo'.

5 Na pesquisa que resultou na minha dissertação (Oliveira, 2006), a análise dos programas e dos textos curriculares do Colégio Pedro II indicou que, apesar de se usar a designação 'Estudos Sociais', ao longo dos anos de 1980 mantiveram-se dois professores para ministrá-las: ao de História couberam os conteúdos da disciplina História e ao de Geografia os conteúdos da disciplina Geografia.

6 O termo é usado por Mesquita (2008) quando a autora se refere aos professores universitários dos cursos de graduação em História que ministravam as disciplinas ligadas ao campo historiográfico.

7 Com esta designação Mesquita (2008) refere-se aos professores cuja preocupação era o ensino da disciplina, sobretudo nos cursos de graduação.

8 É o perfil que, nas empresas, se faz de acordo com cada função nela existente. Neste perfil descreve-se a função, as tarefas a serem realizadas pelo trabalhador e o perfil esperado para esse cargo.

9 A Associação Portuguesa de Geógrafos alertou, em Parecer de novembro de 2006: "A junção da Geografia com a História revela uma visão empobrecedora de ambas as disciplinas, desvalorizando o conhecimento científico na formação de professores, que terá repercussões muito negativas nos discentes portugueses". A Associação de Professores de História declarou na mesma data: "não entendemos de todo que se associem disciplinas como História e Geografia, cujos objectos de estudo e metodologias são tão diferenciadas (...). Como conciliar uma formação na área de docência para professores do $3^{\circ}$ Ciclo e do Ensino Secundário de apenas 100 créditos, com as recomendações do Parlamento Europeu, que aprovou um relatório em que se pede que os programas escolares dos estados-membros incluam um melhor conhecimento da História e dos valores comuns europeus?".

\section{Referências}

Ball, S. (1989). La micropolítica de la escuela: Hacia una teoría de la organización escolar. Barcelona: Paidós.

Ball, S., \& Bowe, R. (1998). El curriculum nacional y su "puesta en práctica": El papel de los departamentos de materias o asignaturas. Revista de Estudios de Curriculum, 1(2), 105-131. 
Burity, J. (2008). Discurso, política e sujeito na teoria da hegemonia de Ernesto Laclau. In D. Mendonça \& L. Rodrigues (Orgs.), Pós-estruturalismo e Teoria do Discurso em torno de Ernesto Laclau. Porto Alegre: EdiPucRs.

De Alba, A. (2007). Currículum-sociedad. El peso de la incertidumbre, la fuerza de la imaginación. México: Plaza y Valdés Editores.

Fernandes, A. T. C. (2008). Estudos sociais no contexto da história brasileira nas primeiras décadas do século XX. In Anais do XIX Encontro Regional de História: Poder, violência e exclusão. ANPUH/SP - USP.

Fernandes, P. (2009). O processo de Bolonha no seu terceiro ano de existência: Olhares diversos para um debate útil. Educação, Sociedade \& Cultura, 28,161173.

García Canclini, N. (2008). Culturas híbridas - Estratégias para entrar e sair da modernidade. São Paulo: Edusp.

Goodson, I. F. (1997). A construção social do currículo. Lisboa: Educa.

Goodson, I. F. (2007). Currículo, narrativa e o futuro social. Revista Brasileira de Educação, 12(35).

Laclau, E. (1993). Poder y representación. In M. Poster (Ed.), Politics, theory, and contemporary culture. Nova York: Columbia University Press.

Laclau, E. (2005). La razón populista. Buenos Aires: Fondo de Cultura Económica.

Laclau, E. (2006). Inclusão, exclusão e a construção de identidades. In A. Amaral Jr. \& J. A. Burity (Orgs.), Inclusão social, identidade e diferença: Perspectivas pósestruturalistas de análise social. SP: Ed. Annablume.

Lopes, A. C. (2005). Política de currículo: Recontextualização e hibridismo. Currículo sem Fronteiras, 5(2), 50-64. Disponível em www.curriculosemfronteiras.org (acesso em janeiro de 2010).

Lopes, A. C. (2007). Currículo e epistemologia (1 ${ }^{a}$ ed.). ljuí: Editora Unijuí.

Lopes, A. C. (2008). Políticas de integração curricular. Rio de Janeiro: EDUREJ.

Lopes, A. C. (2010). A qualidade da escola pública: Uma questão de currículo? Texto apresentado no âmbito do Projeto "Pensar a educação, pensar o Brasil", UFMG [no prelo].

Lopes, A. C., \& Macedo, E. (2011a). Contribuições de Stephen Ball para o estudo de políticas de currículo. In S. Ball \& J. Mainardes (Orgs.), Políticas educacionais: Questões e dilemas. São Paulo: Cortez.

Lopes, A. C., \& Macedo, E. (2011b). Teorias de currículo. São Paulo: Cortez.

Martins, M. C. (2002). A História prescrita e disciplinada nos currículos escolares: Quem disciplina esses saberes? Bragança Paulista: EDUSF.

Mendonça, D., \& Rodrigues, L. P. (Orgs.). (2008). Pós-estruturalismo e Teoria do Discurso em torno de Ernesto Laclau. Porto Alegre: EdiPucRs.

Mesquita, I. M. (2008). Memórias/identidades em relação ao ensino e formação de professores de História (Tese de doutorado). Faculdade de Educação da Universidade Estadual de Campinas, São Paulo.

Mouffe, C. (1996). O regresso do político. Lisboa: Gradiva. 
Oliveira, A. (2006). A disciplina escolar História no Colégio Pedro II: Reinterpretações curriculares dos anos de 1980 aos primeiros anos do século XXI (Dissertação de mestrado). Universidade do Estado do Rio de Janeiro, Rio de Janeiro.

Oliveira, A. (2011a). A disciplina Estudos Sociais nas universidades e escolas: Campo de tensão curricular. In Actas do XI Congresso da SPCE: Investigar, inovar e desenvolver - Desafios das Ciências de Educação [no prelo].

Oliveira, A. (2011b). Repensando a história das disciplinas escolares com base na Teoria do Discurso. In Anais da $34^{a}$ Reunião Anual da Anped. Natal.

Provetti, J. (2009). Sobre a História das Mentalidades. Revista fato\&versões, 1(2), 2009, 97-113. Disponível em www.catolicaonline.com.br/fatoeversoes (acesso em 30 de outubro de 2010).

Rodrigues, H. E. (2009). Lévi-Strauss, Braudel e o tempo dos historiadores. Revista Brasileira de História, 29(5),165-186.

Soares, J.C. (2009). O ensino da Sociologia no Colégio Pedro II (1925-1941) (Dissertação de mestrado). Rio de Janeiro, Universidade Federal do Rio de Janeiro. 


\section{CURRICULAR POLICIES: THE STRUGGLE FOR MEANING IN THE FIELD OF HISTORY}

\section{Abstract}

This article focuses on the performance of the History disciplinary community in the interface that this community establishes with the teaching of this subject and with the curricular policies in Brazil in the 1980s. Based on the matrix of the conception of curriculum that understands as most important the concepts of power and culture, I combine the theoretical-methodological contributions of the History of School Disciplines with other notions, concepts and categories borrowed from Discourse Theory. I present how, in the Brazilian case, a significant number of social actors were involved in multiple processes of articulation and expressed, in texts and through discourse, different tendencies related to the teaching of the discipline History. Finally, I raise possible questions and issues as a result of my analysis of the Decree Law number 43/2007 which, in Portugal, establishes rules regarding the Master Degree in the Teaching of History and the Teaching of Geography, while at the same time I highlight the tension between the disciplines History and Social Studies.

Keywords

Social Studies; Curricular policies; Discourse Theory

\section{POLITIQUES CURRICULAIRES: LA DISPUTE POUR LA SIGNIFICATION DANS LE CHAMPS DE LA DISCIPLINE D' HISTOIRE}

\section{Résumé}

Cet article se concentre sur les actions de la communauté disciplinaire de I'Histoire, l'interface qu'elle entretient avec l'enseignement de la discipline concernée ainsi qu'avec les politiques curriculaires au Brésil, dans les années 1980. En partant d'une conception de curricula qui attribue la centralité de 
ceux-ci au pouvoir et à la culture, le texte articule les apports théoriques et méthodologiques de l'Histoire des Disciplines Scolaires à d'autres notions, des concepts et des catégories prises de la Théorie du Discours. Cela en considérant que, dans le cas du Brésil, un nombre important d'acteurs sociaux ont été impliqués dans plusieurs processus d'articulation et ont exprimée, dans les textes et les discours, des différentes tendances en matière d'enseignement de la discipline Histoire. En conclusion, le texte souligne les questions soulevées par l'analyse du Décret-Loi n 43/2007, qui règle le Master en Enseignement de I'Histoire et de la Géographie au Portugal, mettant en accent les tensions entre I'Histoire et les Études Sociales, en tant que disciplines scolaires.

Mots-clé

Sciences Humaines; Politique du curriculum; Théorie du Discours

Recebido em Agosto/2011

Aceite para publicação em Julho/2012

Toda a correspondência relativa a este artigo deve ser enviada para: Ana de Oliveira; e-mail: anarj49@hotmail.com 